\title{
Insights on K-12 Music Teachers' Retention in Rural, Geographically Isolated Areas: Stories of Success
}

\author{
Amy Haddock* \\ School of Education, Northwest Missouri State University \\ 310 S Walnut, Maryville, MO, 64468, United States \\ E-mail:amyhaddock@outlook.com \\ Nissa Ingraham \\ School of Education, Northwest Missouri State University \\ 800 University Drive, 207 Brown Hall, Maryville, MO, 64468, United States \\ E-mail: nissai@nwmissouri.edu
}

\begin{abstract}
Due to the ever-growing teacher shortage, attention to the retention of teachers, in particular within rural settings, is important. While teacher retention studies have been conducted in lower grades and upper grade level teachers, particular focus on kindergarten through 12 grade music teachers has yet to be done. The overarching objective of this qualitative study was to discover the stories of rural Missouri tenured music teachers and why they chose to remain in their rural place, guided by the conceptual underpinnings of rural education, rural music education, and rural teacher retention. Data collection included interviews with teachers, interviews with administrators, analyzed documents, and analyzed field notes collected from the six different school district building sites employing the participants. Two themes emerged through the six rural teachers' stories: (a) administration and (b) culture. Transparent and bilateral administration communication with administration was coupled with continual student rapport building as overarching subthemes. Recommendations for rural administrators and professors of pre-service music teachers at institutions of higher education and implications for future research relevant in rural music education settings were included.
\end{abstract}

Keywords: Rural music education, Teacher retention, School culture

DOI: $10.7176 / \mathrm{JEP} / 12-24-04$

Publication date:August $31^{\text {st }} 2021$

\section{Scope and Relevance}

Teacher retention is a matter of motivation, according to Skinner's motivation theory, which stated, "human behavior is the result of the arrangement of particular stimuli in the environment" (Merriam \& Bierema, 2014, p. 26). Discovering the motivation of rural music teachers to choose to persevere in their rural school districts is the basis of the following research article. According to Missouri State High School Activity Association (MSHSAA, 2019), in the state of Missouri, there are 119 rural school districts, and 30 of these districts are in the northwest corner of the state. For the purpose of this article the definition of rural is the same as distinction used by MSHSAA (2019) for Class 1. Class 1 schools have between one through 107 students registered in grades nine through eleven. The teacher participants in this study are the sole music teachers employed by the districts at which they serve, thereby, making them geographically isolated. The participants' stories and the thematic based findings reported in this study are the result of the analysis of the qualitative data collected. The conclusions drawn from the analyzed data may be used to guide administrators supervising rural music teachers in similar locations.

\section{Conceptual Framework}

Teacher attrition exists in education as a whole; several studies have found attributes that increase teacher retention (Bates, 2011; Isbell, 2005; Billingsley et al., 2019; Marcoux, 2012). Specifically, within music education, studies have unearthed attributes that can increase teacher retention in rural Kindergarten through $12^{\text {th }}$ grade music positions (Bates, 2011; Isbell, 2005). However, understanding holistically why rural music teachers decide to dedicate themselves to their rural districts remains elusive (Bates, 2011; Isbell, 2005). The conceptual underpinnings of rural education, rural music education and rural teacher retention were the foundation undergirding the discovery of the stories of tenured rural K-12 music teachers.

\subsection{Rural Education}

Rural education has a broad definition (Valentine et. al., 2021; DESE, 2019; MSHSAA, 2019). Rural education hosts similarities and differences to the counterparts of suburban and urban education. By nature, rural education denotes the limited size of student population (MSHSAA, 2019). Rural teachers, staff, and administrators have different burdens placed on them, which their urban and suburban counterparts do not (Williams \& Nierengarten, 
2011). One example of this is the idea of professional development or trainings. According to Williams and Nierengarten (2011), travel time is a distinct source of frustration for rural staff who have long distances to drive for trainings and professional development opportunities, while people working in suburban and urban schools have many close-to-home opportunities for such trainings. This example illustrates the geographic isolation that exists within many rural schools.

Rural educators' course loads vary from one location to the next, many are commonly overwhelmed with a high number of courses to prepare (Robinson, 2012; Missouri Teaching Jobs, 2020). Retaining a rural K-12 music teacher has been found to be problematic without supportive cultures (Ingersoll, 2001). Schein (1992) has found that supportive cultures are contingent upon transparent communication. Levi (2017) illuminated this in his studies on team dynamics and collaboration within the workplace. Leadership can set the tone for organizational culture, climate, and collaboration, and within rural education, the administration is the leader (Bolman \& Deal, 2013; Northouse, 2016; Levi, 2017).

\subsection{Rural Music Education}

Although rural education has been studied (Sher, 2019; Bauch, 2001), a narrower lens exits to allow for further refinement: The content specific area of rural music education (Isbell, 2005; Bates, 2011). Rural music programs are often characterized by the common overload of course preparations by one teacher to include both choir and band (Bates, 2011; Isbell, 2005). A key consideration specific to rural music programs is the student availability of enrolling in music classes, due to conflicting course enrollment limitations (Abril \& Gault, 2008; Isbell, 2005). Two examples are athletes and college preparatory students (Abril \& Gault, 2008). These students can have time conflicts with their personally desired schedules and the band and choir course times (Isbell, 2005). This then, in turn, impacts the rural music teachers' positions and their desire to remain employed rural schools (Isbell, 2005).

\subsection{Rural Teacher Retention}

Teacher retention is a cornerstone of consistency and student academic success (Podolsky et al., 2016; U.S. Department of Education, 2015). Persistent teacher turnover often results in "relational patterns [being] are altered...turnover disrupts the formation and maintenance of staff cohesion and community, it may also affect student achievement" (Boyd et al., 2011, para. 11). For the established K-12 music teachers, rapport building grew with students from one year to the next (Boyd et al., 2011).

Additionally, a strong culture, built over time, was noted as the basis for a successful organization, but without a consistent workforce the culture is threatened of unrest and disconnect (Schein, 1992). One attributing factor of teacher retention is a favorable location and high access to funding, such as a school located in a town that affords luxuries of grocery store options and hair salons (Podolsky et al., 2016). Moreover, teachers were looking for settings that were familiar, thus the teachers exhibited traits, such as altruism, inward strength, and resilience (Chiong et al., 2017; Gu \& Day, 2013). Factors attributing to teacher retention included examples of intrinsic and extrinsic motivation (Chiong et al., 2017).

Boyd et al. (2011) wrote, "Newly hired teachers initially lack essential knowledge and skills to implement an unfamiliar instructional program. The result in settings with persistent turnover then is that schools are continuously starting over" (para 12). Furthermore, Ingersoll (Ingersoll, 2001; Penn CGE News, 2018) reported a high percentage of loss of beginning teachers within the first three years, along with an increasing rate of departure up through the first five years. The ages of the teachers and the content they taught were among the reasons why teachers left the profession (Ingersoll, 2001). On contrast, the notion of teacher retention is denoted by the state of Missouri, through their use of teacher tenure, which is identified by a teacher remaining in a district for five years and successfully being offered a sixth year contract (MSTA, 2019). This study addresses the need for research specifically tailored to the retention of rural music teachers, more specifically for those teaching all levels K-12.

\section{Methods}

This qualitative research employed a bounded multi-case method of collecting and analyzing data (Creswell, 2014; Mertens, 2020). The six participating schools were in the State of Missouri north of Interstate 70, east of Interstate 29, and west of Interstate 35. Each school fit the criteria of both being rural as in smaller student population and employing one tenure status K-12 music teacher (MSHSAA, 2019). Data collection and analysis included review of verbatim transcriptions of recorded interviews with teachers and one principal, documents, and the research observation field notes from each of the six locations (Creswell, 2014).

\subsection{Research Questions}

Due to the lack of research addressing the stories of successful rural tenured K-12 music teachers in northwest Missouri, the study the research sought to answer the following questions: 1 . What factors present at six northwest Missouri rural public-school districts led the retention of each of their solo K-12 music teachers? and 2. 
How do the similarities of these six K-12 music teachers' stories overlap in ways that may help similar districts in other locations in the United States?

\subsection{Setting}

Northwest Missouri was an appropriate setting for researching this topic because the region had the highest density of remote, rural public-school districts in the state of Missouri (MSHSAA, 2019). The geographic region was denoted by MSHSAA (2019) as District 20. This district was selected for the study because of the number of Class 1 schools it contained (MSHSAA, 2019). The definition of a Class 1 school was one with one through 107 students in nineth through eleventh grades. Each of these schools was in a small town surrounded by farmland. Many parts of the adjacent states of Iowa, Kansas, and Nebraska contained similar geography and populations. There were 119 Class 1 schools in Missouri (see Figure 1); 30 of those were in District 20 and the next closest amount was District 19 with only 15 Class 1 schools (MSHSAA, 2021).

\subsection{Selection Process}

To begin, a list was created of Class 1 schools in the selected geographical location, based off of MSHSAA (2019) webpage data. Next, the research conducted a document analysis and investigated the webpages of each school system to determine which districts listed one, sole music educator. The emails of the sole music teachers and principals were obtained, and contact was made. In order to find teachers that had been employed at each district long enough to acquire tenure status, emails were sent out to the teachers and principals asking if the music teachers had tenure. Six teachers met the criteria and responded, denoting they were willing to participate along with four of their principals and two of their superintendents.

\subsection{Participants}

Five of the six teachers identified as female, and one identified as male. To preserve anonymity, each school district was assigned a letter from A to F. Each participating teacher was assigned a pseudonym to preserve anonymity, as emphasized by Creswell (2014). The teachers' ages ranged from 25 to 60 with four of the six being in their 30's and 40's. Three of the six teachers were raising children who attended classes in the same districts where the participant was employed. One teacher enrolled personal children, even though this participant's residence was outside of the school district. Two of the six teachers graduated from a suburban or urban setting, while the other four all graduated from high schools similar to the rural the settings being studied. Over half of the teachers graduated from rural schools. The participants lengths of employment in the district ranged from six years to 30 years (see Table 1 below).

\subsection{Data Collection Process}

In order to augment the trustworthiness of this qualitative study, triangulation was achieved by data collection being derived multiple ways: (a) teacher interviews, (b) principal interviews, (c) document analysis, and (d) field notes (Creswell, 2014; Krueger \& Casey, 2015). The semi-structured, open-ended interviews were recorded verbatim, transcribed, and member checked to increase validity (Seidman, 2013). All participants were allocated a pseudonym to protect their identities (Fink, 2017; Mertens, 2020; Seidman, 2013). The school websites were reviewed. Researcher field notes were taken onsite at the schools (Seidman, 2013). The field notes included observations from the outside of each district location. During the data collection process, the constant comparative method of analysis was used to drive the subsequent questioning and review of documents.

\subsection{Data Analysis}

The qualitative interview utilized open ended questioning beginning with: "What encouragements have you experienced in your position?" This question was followed by a question asking why they came to the location, why they remain, and what is challenging? The questions were chosen based on their abilities to derive the information about the reasons and factors that contributed to the retainment of long-term K-12 music teachers. To end each interview, participants were asked what advice would be given to an administrator from a school district struggling to retain a K-12 music teacher. This question was asked to establish insights into the mindsets of those who remained and what they felt would best serve other districts for creating a similar success.

As teachers and principal were each individually interviewed, a constant comparative method of data analysis was employed guiding subsequent interviews; the answers given helped develop the question(s) wording for the next teacher. In order to understand the theme development and to answer the research questions, the stories of the teachers' retainment were captured.

All names used are pseudonyms. Terry, the first participant, felt encouraged by the students' success as they both prepare for and participate in adjudicated events. Because the scheduling is difficult, Terry has learned over the years that it is important to plan so students are prepared ahead of time when the time conflicts inevitably arise with other activities. Terry and her administrator plan out goals for the year that help them both 
understand the direction of the music program and needs Terry's music students will have. Terry is a member of the community; she sends her own children to the school but also views all her students as her family stating they are "my kids." Terry noted that in her school district much of the administrators, staff, and parents are alumni of the school district which furthers the district feeling like a family. Table 2 below highlights further the sense of family or community built from building a rapport with students over the course of several years.

Another veteran, tenured music teacher, Dotty clearly is most encouraged by the students, finding it most difficult to even consider leaving. When students and others in the community say a kind word, Dotty feels encouraged, "When I'm given a simple thank you." The complexity of the schedule is the most frustrating part of the job for Dotty as she must coordinate her music programs and activities around sports events and another popular rural school club, Future Farmers of America (FFA) and the FFA contests. It is also sometimes challenging to teach students who she has known for so long, because "they argue with me like I'm their mom."

Cathy, a tenured teacher who began as a part-time employee was encouraged, years ago, when her school district changed her from a half-time to a full-time position. Another encouragement for Cathy involved renovations in the building that included a new sound system, creating a more accommodating performance space for her music students. Cathy said, "Parents get their students to the events." Cathy has learned that before and after school music practices regularly conflict with students' vast activity involvements. To compensate for this, Cathy calls on her accommodating fellow staff members to allow students to work on music during lunch and plan times for rehearsal.

Betty, who only recently took on the band portion of the music program, is encouraged by her administration and the decisions and effort they make to support the teachers in the district. Over the years, Betty has taught in many different types of daily schedules and has learned to be flexible and creative. Currently, Betty has developed a course that is flexible allowing for any high school student to develop musically with her guidance on different instruments such as guitar, piano, or drums.

Ally is encouraged by her students and teaching all the students through the years. Ally has struggled with the challenge of core graduation requirements conflicting with her band course, making it impossible for most students to enroll in band all four years. While this scheduling burden is ongoing Ally has learned to appreciate the community support of her vision for her music students.

Jerry is most encouraged by the financial and social support he continually receives from the staff of the school and members of the community. He finds the schedule challenging in that he has less minutes of time with students than he once did, and therefor is not able to prepare them in the same way as before when he had more instructional time with his students. Although Jerry resides in a neighboring district, Jerry would not consider leaving his current employing district because his own two children are now at an age where they are a vital part of the music classes, and this is important to Jerry and his family.

\section{Thematic Findings}

Coding the participants' responses into the main themes was confirmed starting with the first interview with Terry and built upon by each of the following five teacher interviews (Creswell, 2014). Two themes emerged from the coding process: Cultural Support and Administrative Support. Cultural support was mentioned by Terry who talked about setting goals with her principal each year and how the teachers also supported her and how they all worked together. Table 2 isolates other quotations that supported this thematic development. The theme of Administrative Support was highlighted by discussions surrounding interactions between teachers and administration. Participants' responses that aligned with the common emerging theme are found in Table 3. These two themes are more thoroughly expanded below.

\subsection{Cultural Support}

Culture support both within the building walls as denoted by healthy relationships with teachers, parents, and the community was evident in the interviews with all six teachers. Cathy shared that one way she felt supported was the way other teachers helped her prepare students before a performance. Ally shared about learning to sew when community members helped her make flags for the band. Each teacher shared how over the years they had built a rapport with the students, fellow teachers, and the surrounding communities thus aiding in the positive culture.

Terry, a single mom of two, grew up in small town in a neighboring state and was attracted to the area because her family was there. Terry chose to remain in the area because she enjoyed her coworkers. Dotty, in her 50 's, noted she gained the position when she was first hired as a substitute teacher and then later was hired fulltime. Dotty grew up in a slightly larger town than where she currently teaches. Dotty fell in love with the school when she was a substitute teacher mostly due to the students themselves, and the way the staff and community supported the program.

At over 55 years in age Cathy's background included growing up in a suburban area and having taught over 25 years in larger school settings. After a few years of experience in the setting, Cathy's outlook on the position 
was positive. Cathy was impressed with the parent support for the students as evidenced by their consistent presence at events - both inside and outside of the district. Jerry, in his 40's, father of two elementary children. Jerry expressed his strong feelings of having his own children attend school in the district where he taught. The stories shared through the interview processes were supported in the document review and the observation field notes. The schools were well presented in both instances (see Table 2), sharing the symbolic representation of a culture of pride (Bolman \& Deal, 2013). As Schein (1992) shared, culture is pervasive and can create a sense of belonging. That is what was expressed in the interviews with the principals and teachers, and what was present in the document analysis and the on-site observations.

\subsection{Administrative Support}

The second theme that emerged from the data collection and analysis was administrative support. Supportive administration was agreed by all the teachers to be a vital factor in their decisions to remain. Administrative support aspects included communication and being protective of scheduling limitations taking into consideration how music coordinated with core courses, athletics, and other student organizations. The interview data found in Table 3 further reveals specific responses from participants outlining administrative support.

Terry and her principal begin each year by discussing and defining goals for the year. Similarly, Betty's first principal encouraged her in numerous ways. Although Betty grew up in a similarly sized school, she found the first year of teaching to be extremely challenging. The principal offered valuable mentorship that Betty values even now that she has been in the position for 18 years. In her sixth year of teaching, Ally was hired right after finishing her teaching degree in her 20's, and the support she was given by her principal was invaluable. The final teacher interview was with the only male teacher to be interviewed, and he also conveyed the importance of the administrator support. These ideas were seen in the postings on the school websites, while conducting the document analysis. There were pictures that included the administrators of the schools, symbolizing that they see themselves as a part of the larger team (Bolman \& Deal, 2013). Additionally, Levi (2017) and Northouse (2016) supported the notion that a supportive and collaborating leader can create an environment where people want to not only work but thrive in their positions at work. These aspects regarding a collaborative leader resonated throughout the data. See Table 4 for further listings of the themes by assigned district letter.

\section{Conclusions}

The conclusions drawn from the findings of this research provide contributions to the field of education to rural administrators who supervise K-12 music staff, scholars with interest in phenomenon of rural music teacher retention, and stake holders involved in higher education in proximity to rural areas preparing preservice music teachers. The data from all six teachers revealed the frustration of scheduling conflicts that interfered with their students' participation in the music programs. Likewise, all six districts shared a supportive administrations and cultures. The tenured music teachers in rural northwest Missouri studied revealed that one reason they have remained in K-12 positions was due to the rapport established between themselves, other faculty members, their administration, and the students. Administrative support included the act of listening and implementing schedules with the music program in mind. Community or cultural support examples included the giving of time in various ways, such as by attending music events and by driving students to high school festivals and auditions. While each teacher gained years at their respective school districts, they simultaneously built good communication lines of communication.

Professors in higher education and fellow music educators who use language such as starter positions, when listing or discussing rural K-12 job openings (MSSBDA, 2020; Bates, 2011) should reconsider. Rural settings need teachers with experience who are willing to remain long term. New teachers entering challenging rural positions who view the job as a possible steppingstone, put students at a disadvantage. Music professors from institutions of higher education who implement mindful plans to identify, prepare, and equip well-suited pre-service teachers to remain in rural K-12 music set up students for greater success. Rural researchers interested in issues of rural K-12 music teachers could start by investigating the frequency of the use of language such as starter job when announcing open positions. Stepping-stone terminology should be avoided when creating or discussing rural K-12 music positions (Missouri Small-School Band Directors, 2020; Bates, 2011). This type of labeling contributes to the way a new teacher views the length of time to remain in the rural setting.

\subsection{Future Research}

Future research considerations include reviewing the quantitative data of retained K-12 music teachers, utilizing this study's themes as indicators to create on a statewide survey. Additionally, the integration of technology, for sole K-12 music teachers to create informal professional development and content-specific support from one location to another could be another lens for future studies (Hu, 2005). Implications for additional research include incorporating the impact of COVID on teacher retention in rural music education (Bolt \& Yadav, 2021). 


\section{References}

Abril, C. R., \& Gault, B. M. (2008). The state of music in secondary schools: The principal's perspective. Journal of Research in Music Education, 56(1), 68-81. https://doi.org/10.1177/0022429408317516

Bates, V. C. (2011). Preparing rural music teachers: reflecting on "shared visions." Journal of Music Teacher Education, 20(2), 89-98. https://doi.org/10.1177/1057083710377722

Bauch, P. A. (2001). School-community partnerships in rural schools: Leadership, renewal, and a sense of place. Peabody Journal of Education, 76(2), 204-221. https://doi.org/10.1207/S15327930pje7602_9

Billingsley, B., Bettini, E., Jones, N. D., McLeskey, J., Billingsley, B. S., Brownell, M. T., \& Maheady, L. J. (2019). Supporting special education teacher induction through high-leverage practices. Remedial \& Special Education, 40(6), 365-379. https://doi-org.ezproxy.nwmissouri.edu/10.1177/0741932518816826

Bolman, L. G. \&, Deal, T. E. (2013). Reframing organizations: Artistry, choice, \& leadership (5th ed.). JosseyBass.

Bolt, L. \& Yadav, A. (2021). Transitioning to remote learning: Lessons from supporting K-12 teachers through MOOC. British Journal of Education Technology, 52(4). 1377-1393.

Boyd, D., Grossman, P., Ing, M., Lankford, H., Loeb, S., \& Wyckoff, J. (2011). The influence of school administrators on teacher retention decisions. American Educational Research Journal, 48(2), $303-333$. https://doi.org/10.3102/0002831210380788

Chiong, C., Menzies, L., \& Parameshwaran, M. (2017). Why do long-serving teachers stay in the teaching profession? Analyzing the motivations of teachers with 10 or more years' experience in England. British Educational Research Journal, 43(6), 1,083-1,110. https://doi.org/10.1002/berj.3302

Creswell, J. W. (2014). Research design qualitative, quantitative \& mixed methods approaches. Sage.

Fink, A. (2017). How to conduct surveys: A step by step guide. Sage Publishing.

Gu, Q., \& Day, C. (2013). Challenges to teacher resilience: Conditions count. British Educational Research Journal, 39(1), 22-44. https://doi.org/10.1080/01411926.2011.623152

Hu, G. (2005). Professional development of secondary EFL teachers: Lessons from China. Teachers College Record, 107(4), 654-705.

Ingersoll, R. M. (2001). Teacher turnover and teacher shortages: an organizational analysis. American Educational Research Journal, 38(3), 499-534. https://doi.org/10.3102/00028312038003499

Isbell, D. (2005). Music education in rural areas: A few keys to success. Music Educators Journal, 92(2), 30-34. https://doi.org/10.2307/3400194

Krueger, R. A., \& Casey, M. A. (2015). Focus groups: A practical guide for applied research (5th Ed.). Sage.

Levi, D. J. (2017). Group dynamics for teams (5th ed.). Sage.

Merriam, S. B., \& Bierema, L. L. (2014). Adult learning: Linking theory and practice. Jossey-Bass.

Merriam, S. B., \& Tisdell, E. J. (2016). Qualitative research: A guide to design and implementation (4th ed.). Jossey-Bass.

Mertens, D. (2020). Research and evaluation in education and psychology: integrating diversity with quantitative, qualitative, and mixed methods. SAGE.

Missouri Department of Elementary and Secondary Education. (2021, July 5). Missouri school directory.file:///C:/Users/nissai/AppData/Local/Temp/School\%20Directory\%20(All\%20Districts).pdf

Missouri State High School Activities Association (MSHSAA). (2019). Music activities. https://www.mshsaa.org/Activities/Info/MusicActivities.aspx

Missouri State High School Activities Association. (MSHSAA). (2021). https://www.mshsaa.org/Activities/Info/MusicActivities

Missouri Small School Band Directors Association. https://sites.google.com/laqueyhornets.us/mssbda/history?authuser=0

Missouri Teaching Jobs. (2020). MO Teaching Jobs. www.moteachingjobs.com

MSTA. (2019). Missouri schools teacher association. school laws guide. https://www.msta.org/wpcontent/uploads/2018/10/school-Law-Guide-WEB.pdf

Northouse, P. G. (2016). Leadership: Theory and practice. Sage.

Penn GSE News. (2018, October 23). Richard Ingersoll updates landmark study of the American teaching force, now covering 3 decades. https://www.gse.upenn.edu/news/press-releases/richard-ingersoll-updateslandmark-study-american-teaching-force-now-covering-3

Podolsky, A., Kini, T., Bishop, J., \& Darling-Hammond, J. (2016). Solving the teacher shortage: how to attract and retain excellent educators. Learning Policy Institute.

Robinson, N. R. (2012). Preservice music teachers' employment preferences: Consideration factors. Journal of Research in Music Education, 60(3), 294-309. https://doi.org/10.1177/0022429412454723

Schein, E. H. (1992). Organizational culture and leadership. Jossey-Bass.

Seidman, I. (2013). Interviewing as qualitative research: A guide for researchers in education \& the social sciences. Teachers College Press. 
U.S. Department of Education. (2015). Every student succeeds act. https://www.ed.gov/essa?src=ed-search Sher, J. P. (2019). Rural education In urbanized nations: Issues and innovations. Routledge.

Valentine, A., Gemin, B., Vashaw, L.,Watson, J., Harrington, C., LeBlanc, E. (2021). Digital learning in rural K-12 settings: A survey of challenges and progress in the United States. IGI Global. DOI: 10.4018/978-17998-8047-9.ch099

Williams, J. M., \& Nierengarten, G. (2011). Recommendations from the North Star State: Rural administrators speak out. Rural Educator, 33(1), p. 15-25.

Table 1. Participants' number of years in the district

\begin{tabular}{|c|c|c|c|c|}
\hline School District & Pseudonym & Teacher & Principal & Superintendent \\
\hline A & Terry & 8 & $5+$ & NA \\
\hline B & Dotty & 18 & $5+$ & NA \\
\hline C & Cathy & 8 & NA & 30 \\
\hline D & Betty & 17 & $5+$ & NA \\
\hline E & Ally & 6 & 1 & 1 \\
\hline F & Jerry & 18 & NA & NA \\
\hline
\end{tabular}

Length of employment for each participant at current district.

Table 2. Culture support theme quotes Participants

Quotations

\begin{tabular}{|c|l|}
\hline Dotty & $\begin{array}{l}\text { "you just got to find a time to be able to work for [with] } \\
\text { everybody...sports practices, you've got to work around that." }\end{array}$ \\
\hline Cathy & $\begin{array}{l}\text { "there's a last period at our school...if I have kids that can't fit into the } \\
\text { band ...and choir, we actually do that during seminar time." }\end{array}$ \\
\hline Jerry & $\begin{array}{l}\text { "And, you know, I like the passion that I see with the kids... and they } \\
\text { really do go all out, even though they're also involved in cheerleading, } \\
\text { football, baseball, you know all the stuff." }\end{array}$ \\
\hline " ...listen to ideas...keep an open mind." \\
\hline Terry's Principal & $\begin{array}{l}\text { "There were not adequate resources in my school and my district } \\
\text { supported me. I would come back from a convention and go 'this, this } \\
\text { this this and this...may I get these? Boom! And they would purchase it } \\
\text { for me" }\end{array}$ \\
\hline "Wlly & $\begin{array}{l}\text { "Well I'm a color guard coach and I started them from the ground up like } \\
\text { last couple of years donated money for poles.... We make our silks...I've } \\
\text { never sewn in my life... and two parents taught me how to sew" }\end{array}$ \\
\hline
\end{tabular}

Participants' responses leading to the emerging theme of cultural support.

Table 3. Administrative support theme quotes

\begin{tabular}{|l|l|}
\hline Participants & \multicolumn{1}{c|}{ Quotes } \\
\hline Dotty's Principal & $\begin{array}{l}\text { "we do our best to schedule classes in ways that protect these electives." } \\
\text { "Help when you can...encourage the teacher, make it (music program) a priority." }\end{array}$ \\
\hline $\begin{array}{l}\text { Cathy's } \\
\text { Superintendent }\end{array}$ & "We switched to the district providing most of our band instruments." \\
\hline Terry & $\begin{array}{l}\text { The administration is transparent and communicates with the teacher and also they make the } \\
\text { teacher feel comfortable communicating what they need..." }\end{array}$ \\
\hline Ally's Principal & $\begin{array}{l}\text { "[if] you're not developing that person into being that [rapport builder] type of teacher, then } \\
\text { your program is dead in less than 3 years." }\end{array}$ \\
\hline Betty & $\begin{array}{l}\text { "My elementary principal walked down to my classroom every day for the first two weeks, } \\
\text { probably longer. And she would kind of pat me on the arm and say "go home, you can't } \\
\text { learn it all in one day. It's fine. Go home." }\end{array}$ \\
\hline Jerry & $\begin{array}{l}\text { "We just passed a bond to get a new elementary wing built. ...there's definitely support } \\
\text { there" }\end{array}$ \\
\hline
\end{tabular}

Participants' responses leading to the emerging theme of administrative support. 
Table 4. Emerging key themes from participants from all six districts

\begin{tabular}{|c|c|c|}
\hline Districts & Culture Support & Administrative Support \\
\hline A & $\mathrm{X}$ & $\mathrm{X}$ \\
\hline $\mathrm{B}$ & $\mathrm{X}$ & $\mathrm{X}$ \\
\hline $\mathrm{C}$ & $\mathrm{X}$ & $\mathrm{X}$ \\
\hline $\mathrm{D}$ & $\mathrm{X}$ & $\mathrm{X}$ \\
\hline $\mathrm{E}$ & $\mathrm{X}$ & $\mathrm{X}$ \\
\hline $\mathrm{F}$ & $\mathrm{X}$ & $\mathrm{X}$ \\
\hline
\end{tabular}

All six districts unanimously support both emerging themes.

25

20

15

10

5

0

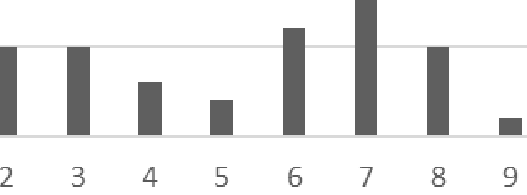

10

Figure 1. District 20 in northwest Missouri contains the most Class 1 schools in the state 